\title{
Antibiotic prescribing in general practice and hospital admissions for peritonsillar abscess, mastoiditis, and rheumatic fever in children: time trend analysis
}

M Sharland, H Kendall, D Yeates, A Randall, G Hughes, P Glasziou, D Mant

Editorial by Little

Paediatric Infectious Diseases Unit, St George's Hospital, London SW17 0QT

M Sharland

consultant in paediatric infectious diseases

\section{Pharmaceutical}

Directorate,

Prescription Pricing

Authority,

Newcastle upon

Tyne NE1 6SN

H Kendall

prescribing services

manager

Oxford University

Division of Public

Health and Primary

Care, Oxford

OX3 7LF

D Yeates

computer scientist,

health care

epidemiology unit

A Randall

clinical tutor

P Glasziou

professor of evidence

based medicine

D Mant

professor of general

practice

GPRD Division,

Medicines and

Healthcare

Products

Regulatory Agency,

London SW8 5NQ

G Hughes

senior research

scientist

Correspondence to:

D Mant

david.mant@

dphpc.ox.ac.uk

BMJ 2005;331:328-9
Antibiotic resistance is an increasing problem in paediatric practice. General practitioners in the United Kingdom have consequently been exhorted to minimise antibiotic prescribing for childhood upper respiratory infections. ${ }^{1}$ However, some data suggest an association between reduced prescribing and an increased incidence of rare complications of bacterial infection. ${ }^{2-4}$ We report national data on community prescribing of antibiotics and hospital admissions for peritonsillar abscess, mastoiditis, and rheumatic fever in children during 1993-2003 (community prescribing) and 1993-2002 (hospital admissions).

\section{Participants, methods, and results}

We took prescribing data from the Prescription Pricing Authority's database for England (which collates information on drugs issued by pharmacists) and from the IMS Disease Analyzer Mediplus UK
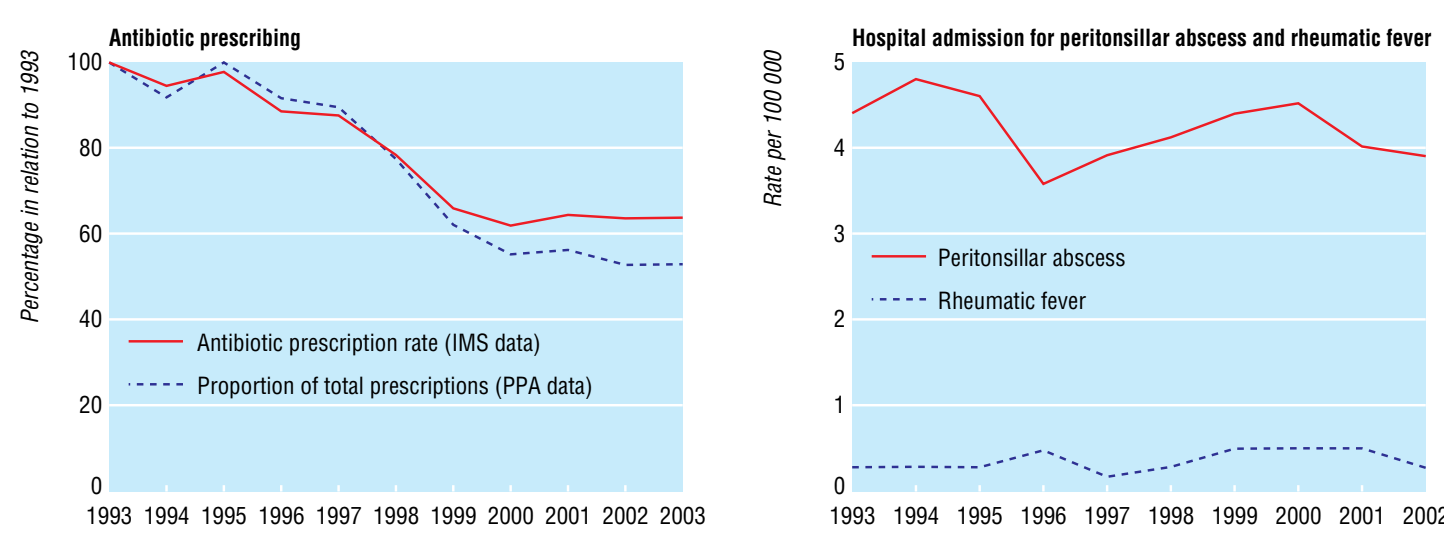

1993199419951996199719981999200020012002

Year
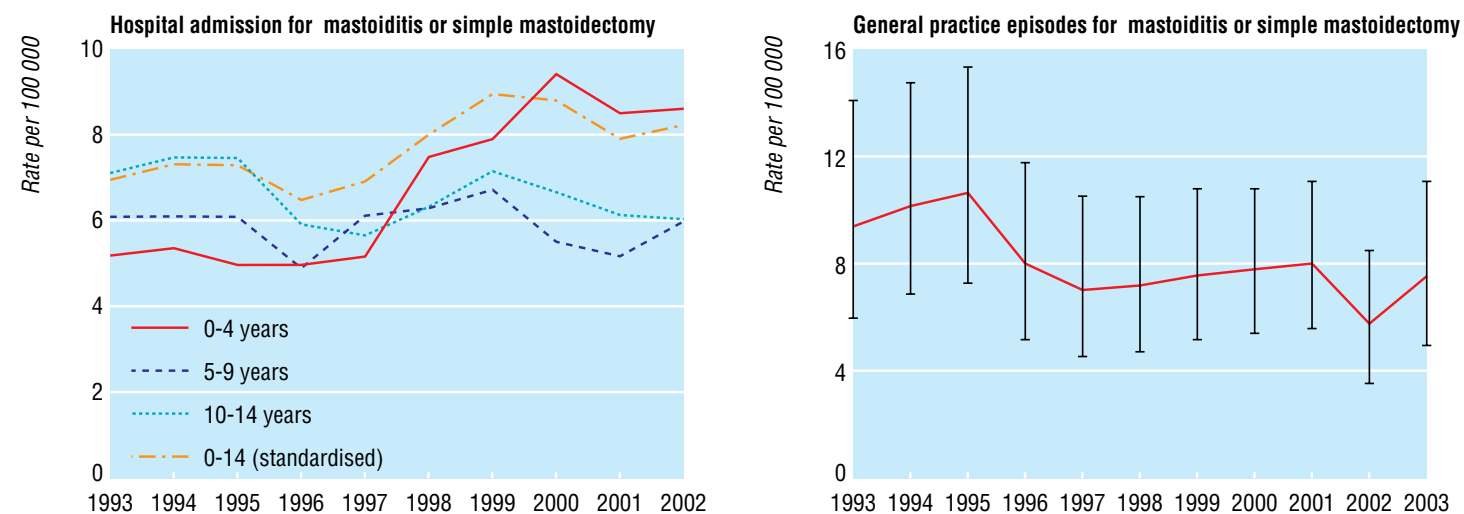

19931994199519961997199819992000200120022003

database (which contains electronic consultation data from about 130 computerised practices). We extracted hospital admission data from the hospital episode statistics for England using coding from the international classification of diseases, ninth and 10th revisions (ICD-9, ICD-10): 475 and J36 (quinsy); 390-2 and I00-I02 (rheumatic fever); and 383 and H70 (mastoiditis). The operation codes (OPCS 3 and OPCS 4) that we used for identifying cases of simple or cortical mastoidectomy were 200, 201.2, 201.9, D10.3, and D10.4, but we excluded cases with tympanoplasty or myringoplasty (193, 194.1, 194.2, D14.1, D14.2, and D15). General practice consultation and referral data from the Medicines and Healthcare Products Regulatory Authority's general practice research database were extracted for children aged

This article was posted on bmj.com on 20 June 2005: http://bmj.com/cgi/doi/10.1136/bmj.38503.706887.AE1

Time trends in antibiotic prescribing to children and episodes of, and admissions for mastoiditis, peritonsillar abscess, and rheumatic fever, in United Kingdom, 1993 to 2002 or 2003 (95\% confidence intervals [for general practice episodes] are based on Poisson approximation). PPA=Prescription Pricing Authority. 
$\leq 15$ years by using the following event codes: OXMIS 3829, 3830, 3839 or READv2 F53, F530, F530z, and F5300 (mastoiditis); and OXMIS K201 or READv2 7310, 73102, 73103, and 73104 (simple or cortical mastoidectomy).

The figure shows the decline in the prescribing rate of antibiotics by general practitioners between 1993 and 2003. The most substantial decline (34\%) occurred before 1999; the number of antibiotic prescription items issued by pharmacists fell by a similar amount (38\%). After 1999, prescribing by general practitioners seemed to level off, falling only by a further $3 \%$. The number of antibiotic items issued continued to fall, however, by a further $9 \%$.

From 1993 to 2002, hospital admissions for peritonsillar abscess and rheumatic fever did not increase, whereas hospital admission rates for mastoiditis and simple mastoidectomy increased by $19 \%$ (from 6.9/100 000 to 8.2/100 000) (figure). This rise was attributable predominantly to an increase in admissions (from 5.2/100 000 to 8.6/100 000) among children aged $\leq 4$ years, the children in whom otitis media is common. The period of sharpest rise (1996-9) coincided with the substantial fall in antibiotic prescribing. However, the data from the general practice research database did not confirm an increase in mastoiditis or referral for mastoidectomy. In fact, the trend seems to be downwards-from 9.4/100 000 in 1993 to $7.6 / 100000$ in 2003 (figure).

\section{Comment}

Over the past decade in England, antibiotic use resulting from general practice prescribing of antibiotics to children has halved, and this reduction has not been associated with an increase in admission to hospital for peritonsillar abscess or rheumatic fever. The decline in use was due initially to a substantial reduction in prescribing by general practitioners. After 1997 the proportion of prescriptions taken to a pharmacist also declined, possibly indicating that general practitioners were adopting the "delayed prescribing" policy (issuing prescriptions with advice to parents to wait and see if their child's condition improved spontaneously) that was introduced after widespread dissemination of trial results supporting this practice. ${ }^{5}$

Data on mastoiditis and simple mastoidectomy are conflicting. The apparent increase in hospital events could reflect coding error. The reduction in general practice events could reflect the fact that children with suspected serious complications such as mastoiditis are increasingly being taken direct to hospital. The best previous estimate is that a minimum of 2500 children need to be treated with an antibiotic to prevent one case of mastoiditis, ${ }^{2}$ but we believe this may be a conservative estimate.

We thank Richard Wise (chairman of the government's Specialist Advisory Committee on Antimicrobial Resistance (SACAR)) for his thoughtful comments on the first draft of this paper.

Contributors: The decision to conduct the study was made by the SACAR paediatric subgroup. The work was initiated and led by MS and DM, who also drafted the paper. Data extraction and source analysis was done by HK (data from the Prescription Pricing Authority), AR (IMS data), GH (data from the general practice research database), and DY (hospital episode statistics). PG is author of the Cochrane review on antibiotic prescribing for otitis media; he commented on a series of drafts and

\section{What is already known on this topic}

The UK government is to reduce antibiotic prescribing to children in general practice with upper respiratory tract infections to minimise antibiotic resistance

Some data suggest an association between reduced prescribing and an increased incidence of rare complications of bacterial infection and hospital admissions

\section{What this study adds}

A fall of $50 \%$ in the prescribing of antibiotics to children in English general practice has not been accompanied by an increase in hospital admissions for peritonsillar abscess or rheumatic fever

provided statistical expertise. Collation of data, compilation of the figure, and final drafting were done by DM. All authors commented on the final draft. DM is the guarantor.

Funding: Data from the IMS Disease Analyzer Mediplus UK database and from the Prescriptions Pricing Authority were provided free. The Department of Health provided funding for buying the data on the general practice research database from the Medicines and Health Care Product Regulatory Authority.

Competing interests: None declared.

Ethical approval: Not needed.

1 Department of Health Standing Medical Advisory Committee Subgroup on Antimicrobial Resistance. The path of least resistance-main report. group on Antimicrobial Resistance. The path of least resistance-main repor
London: DoH, 2000. www.advisorybodies.doh.gov.uk/smac1.htm

2 Van Zuijlen DA, Schilder AG, Van Balen FA, Hoes AW. National Van Zujlen DA, Schilder AG, Van Balen FA, Hoes AW. National
differences in incidence of acute mastoiditis: relationship to prescribing patterns for acute otitis media. Pediatr Infect Dis J 2001;20:140-4.

3 Little P, Watson L, Morgan S, Williamson I. Antibiotic prescribing and admissions with major suppurative complications of respiratory tract infections: a data linkage study. BrJ Gen Pract 2002;52:187-90.

4 Majeed M, Williams S, Jarman B, Aylin P. Dr Foster's case notes: prescribing of antibiotics and admissions for respiratory tract infections in England. BMJ 2004;329:879.

5 Arroll B, Kenealy T, Kerse N. Do delayed prescriptions reduce antibiotic use in respiratory tract infections? A systematic review. $\mathrm{Br} \mathrm{J} \mathrm{Gen} \mathrm{Pract}$ 2004;53:871-7.

(Accepted 18 May 2005)

doi 10.1136/bmj.38503.706887.AE1

\section{Endpiece}

\section{Second opinions}

In this country it is the usage frequently to employ practitioners who are considered as of less note at the beginning of a complaint; and afterwards, if he should not be thought capable of conducting, or if he should not cure the disease, another is sent for, as supposed of greater skill. I do not mean to argue the propriety of this usage; but as it exists that this second practitioner can obtain very little authentic evidence of what went before in this disease, by which he can judge of it.

Fordyce G. An attempt to improve the evidence of medicine. Trans Soc Impr Med Chir Knowl $1793 ; 1: 244$

Submitted by Jeremy Hugh Baron, honorary professorial lecturer, Mount Sinai School of Medicine, New York 